\title{
Bleeding Incidence in Patients Administered with Warfarin at Secondary Hospitals in Yogyakarta Province
}

\author{
Vitarani D.A Ningrum ${ }^{1}$, Sufiyah ${ }^{2}$, Irine Dyah Widyastuti ${ }^{3}$, Bacrie Sufriyanto Yusuf ${ }^{4}$ and Wahyudin \\ Dullah $^{4}$ \\ 1. Department of Pharmacy, Universitas Islam Indonesia, Sleman, Daerah Istimewa Yogyakarta, Indonesia 55584 \\ 2. Senior Clinical Pharmacist at Sleman Regional Public Hospital, Sleman, Daerah Istimewa Yogyakarta, Indonesia \\ 55514 \\ 3. Senior Clinical Pharmacist at Bethesda Hospital, Yogyakarta, Daerah Istimewa Yogyakarta, Indonesia \\ 55224 \\ 4. Research Assistant at Department of Pharmacy, Universitas Islam Indonesia, Sleman, Daerah Istimewa \\ Yogyakarta, Indonesia 55584
}

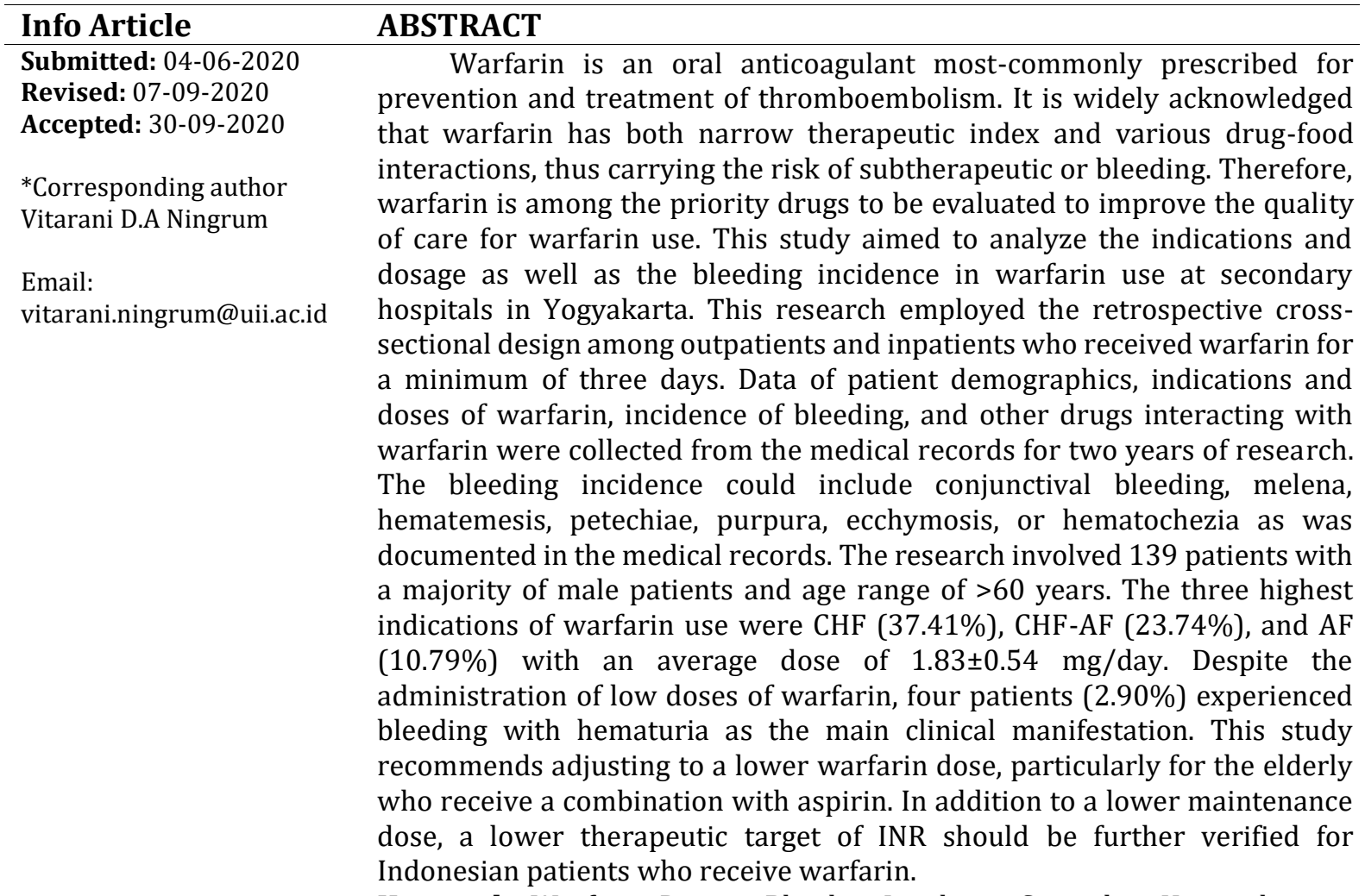

Keywords: Warfarin, Dosage, Bleeding Incidence, Secondary Hospital

\section{INTRODUCTION}

As an oral anticoagulant approved by the FDA since 1950s, warfarin remains the first-line treatment as a prophylactic and therapy for venous thromboembolism, thromboembolic complications, as well as myocardial infarction and stroke. Although direct oral anticoagulants (DOACs), including dabigatran and rivaroxaban listed in the 2018 national formulary, are currently available, the use of warfarin remains high in a number of healthcare facilities in Indonesia. A meta-analysis study reported that DOACs provide a slight improvement in effectiveness and safety when compared to warfarin to prevent stroke in patients with atrial fibrillation but at a higher cost, thus requiring further comprehensive consideration when making a decision to administer (Canestaro et al., 2013; Ruff et al., 2014).

However, warfarin exhibits a very narrow therapeutic index $(1-10 \mu \mathrm{g} / \mathrm{mL})$ (Ritschel \& Kearns, 2004), clinically significant interactions with 
numerous types of drug and food (Bungard et al., 2011; Teklay et al., 2014), and metabolic variation which is strongly influenced by genetic polymorphisms, making it challenging to predict the pharmacological effects (Mak et al., 2019; Suriapranata et al., 2011) and variety of dose requirement (Ta Michael Lee \& Klein, 2013). In addition, data from the FDA also indicated that warfarin was among the ten drugs with the highest number of adverse events reported during the 1990-2000 decade. Meanwhile, data from the Emergency Department during 1999-2003 showed that warfarin was associated with 29,000 hospital visits due to bleeding-related complications annually (Wysowski et al., 2007). Therefore, following the criteria from the WHO and Ministry of Health of the Republic of Indonesia, warfarin is among the top priority of drug use evaluation (Kemenkes RI, 2019a; World Health Organization, 2003).

A number of studies to evaluate the use of warfarin have been conducted in different countries (Khalili et al., 2010; Laäs \& Naidoo, 2018; Semakula et al., 2020), including Indonesia (Agustini et al., 2016; Furdiyanti et al., 2014; Putri et al., 2012). These studies, however, focused more on evaluating the doses associated with INR (International Normalized Ratio) control while those in Indonesia involved a limited number of patients. In essence, studies of bleeding incidence due to warfarin with its therapeutic doses as well as investigations of clinical manifestations associated with the interaction between warfarin and other drugs are required to provide an optimal use of warfarin with a minimum risk of fatal bleeding. Therefore, this present study analyzes the indications and doses as well as incidence of bleeding associated with warfarin use and its drug interactions among the outpatients and inpatients of secondary hospitals in Yogyakarta Province.

\section{MATERIAL AND METHODS}

A retrospective cross-sectional study of warfarin use was conducted at Bethesda Hospital in Yogyakarta Municipality and at Sleman Regional Public Hospital involving patients who received warfarin from January 2016 - December 2017 with the data collection and analysis carried out between July 2018 to February 2019. This study analyzed the use of warfarin in adult patients with a minimum of three days of prescription while those given a change in the anticoagulant drug or experiencing chronic liver failure and blood coagulation disorders were excluded. Using the saturation sampling technique, all patients who met the inclusion criteria were involved in the study. Demographic characteristics of patients as well as diagnosis, warfarin dose, and bleeding incidence data were obtained from the medical records. The incidence of warfarin-associated bleeding could manifest as conjunctival bleeding, melena, hematemesis, petechiae, purpura, ecchymosis, or hematochezia in accordance with the medical records. INR values or decreased $\mathrm{Hb}$ levels were used to confirm the bleeding incidence. To minimize the potential for bias toward bleeding incidence caused by concurrent use of other drugs and warfarin, this study also analyzed the incidence of warfarin drug interactions in which the other drugs should have reached at least the steady state levels corresponding to their half-lives. A univariate analysis was employed to display the data of demographic characteristics, diagnosis, and warfarin doses in mean \pm SD using the Excel program in Microsoft Office 365. In addition, the incidence of warfarin-associated bleeding was presented as a percentage while the difference in means of warfarin doses per age category in each diagnosis was analyzed using the T-test for normally-distributed data or the Mann-Whitney test otherwise (SPSS Version 25). This study has passed the ethical review from the Ethics Committee of the Faculty of Medicine of Universitas Islam Indonesia with protocol No. 12/Ka.Kom.Et/70/KE/III/2018 and of the Faculty of Medicine of Universitas Kristen Duta Wacana with protocol No. 582/C.16/F/2018.

\section{RESULTS AND DISCUSSION}

A total of 139 patients with 233 visits consisting of both outpatients and inpatients were involved in this study. The flow diagram of patients participating in this study (Figure 1).

Since the research location was secondary hospitals, this study found no patients with the exclusion criteria of bleeding disorders, such as hemophilia and Von Willebrand disease that must usually be referred to a tertiary hospital. Additionally, there were no patients with chronic liver failure who had impaired coagulation factor synthesis in this study. Therefore, all patients who met the inclusion criteria were involved up to the end of the study. The patient characteristics according to age and sex as well as data of diagnoses that indicated warfarin administration (Table I). 


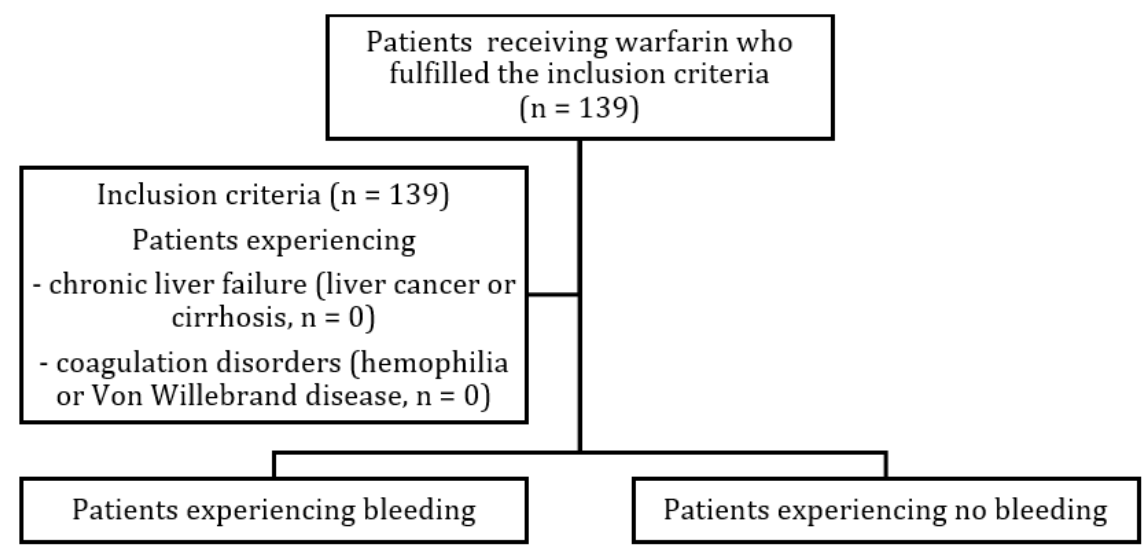

Figure 1. Flowchart of subjects in this retrospective cross-sectional study.

Table I. Characteristics of Patients.

\begin{tabular}{lcc}
\hline Characteristic & Total (n) & Percentage (\%) \\
\hline Sex & & \\
Male & 85 & 61.15 \\
Female & 54 & 38.85 \\
Age (years) & & \\
Adult (18-60) & 58 & 41.73 \\
Elderly (>60) & 81 & 58.27 \\
Diagnosis & 15 & \\
AF & 33 & 10.79 \\
AF, CHF & 6 & 23.74 \\
AF, CVA NH & 1 & 4.32 \\
AF, DVT & 52 & 0.72 \\
CHF & 1 & 37.41 \\
CHF, AF, CVA NH & 1 & 0.72 \\
CHF, CVA NH & 2 & 0.72 \\
CHF, DVT, AF & 3 & 1.44 \\
CHF, DVT & 11 & 2.16 \\
CVA NH & 12 & 7.91 \\
DVT & 1 & 8.63 \\
MVR & 1 & 0.72 \\
Post elective SC with APS & & 0.72 \\
\hline
\end{tabular}

Note: Indications include Atrial Fibrillation (AF), Congestive Heart Failure (CHF), Cerebrovascular Accident Non Hemorrhagic (CVA NH), Deep Vein Thrombosis (DVT), Mitral Valve Replacement (MVR), Post elective SC with APS: blood clotting disorders that lead to thrombosis in the arteries and veins and can cause miscarriage, APS: Antiphospholipid Antibody Syndrome

This study found that the majority of patients receiving warfarin were men and the elderly. In general, the prevalence of cardiovascular disease in developed countries is higher among female elderly patients. This finding is in line with the higher life expectancy of women, and the epidemiological data thus show that women are at greater risk than men (Mosca et al., 2011). This condition also occurs in Indonesia as the 2018 Basic Health Research reported that women became the group with the highest prevalence of cardiovascular disease and its predispositions, including diabetes mellitus, hypertension, and heart disease, but not stroke since its incidence rate in men was $0.1 \%$ higher compared to that of women (Kemenkes RI, 2019b). 
Table II. Average Warfarin Dose for Each Diagnosis Category and Age Group

\begin{tabular}{|c|c|c|c|c|}
\hline \multirow{2}{*}{$\begin{array}{l}\text { Diagnosis } \\
\mathrm{CHF}\end{array}$} & \multirow{2}{*}{$\begin{array}{c}\text { Age } \\
\text { Adult }\end{array}$} & \multirow{2}{*}{$\begin{array}{c}\mathbf{N} \text { (visit) } \\
59\end{array}$} & \multicolumn{2}{|c|}{ Average Dose (mg/day $\pm S D)$ and p-value* } \\
\hline & & & $1.75 \pm 0.64$ & \\
\hline & Elderly & 72 & $1.89 \pm 0.54$ & 0.035 \\
\hline \multirow{2}{*}{$\mathrm{CHF}, \mathrm{AF}$} & Adul & 16 & $1.63 \pm 0.70$ & \multirow[b]{2}{*}{0.313} \\
\hline & Elderly & 18 & $1.89 \pm 0.32$ & \\
\hline \multirow[t]{3}{*}{ CHF, DVT } & Adult & 2 & $2.00 \pm 0$ & \multirow{3}{*}{ - } \\
\hline & Elderly & 2 & $1.66 \pm 0.23$ & \\
\hline & Adult & 1 & 1.5 & \\
\hline CHF, DVT, AFNVR & Elderly & 1 & 2 & \multirow{3}{*}{-} \\
\hline \multirow{2}{*}{$\mathrm{CHF}, \mathrm{AF}, \mathrm{CVA} \mathrm{NH}$} & Adult & 1 & 2 & \\
\hline & Elderly & 1 & 1.5 & \\
\hline \multirow[t]{2}{*}{ CHF, CVA NH } & Elderly & 1 & 1.33 & - \\
\hline & Adult & 15 & $2.00 \pm 0.33$ & \multirow{2}{*}{0.012} \\
\hline \multirow[t]{2}{*}{$\mathrm{AF}$} & Elderly & 12 & $1.65 \pm 0.41$ & \\
\hline & Adult & 6 & $1.92 \pm 0.20$ & \multirow{2}{*}{0.514} \\
\hline DVT & Elderly & 7 & $1.77 \pm 0.50$ & \\
\hline \multirow[t]{2}{*}{$\mathrm{AF}, \mathrm{CVANH}$} & Elderly & 5 & $1.86 \pm 0.26$ & - \\
\hline & Adult & 4 & $1.88 \pm 0.25$ & \multirow{2}{*}{0.161} \\
\hline CVA NH & Elderly & 7 & $2.03 \pm 0.08$ & \\
\hline Post elective SC with APS & Adult & 1 & 0.36 & - \\
\hline AF, DVT & Adult & 1 & 2 & - \\
\hline MVR & Elderly & 1 & 4 & - \\
\hline
\end{tabular}

Note: Indications include Congestive Heart Failure (CHF), Deep Vein Thrombosis (DVT), Atrial Fibrillation (AF), Cerebrovascular Attack (CVA), Cerebrovascular Accident Non Hemorrhagic (CVA NH), Mitral Valve Replacement (MVR), Post elective SC with APS: after caesarean section with APS (Antiphospholipid Antibody Syndrome); ${ }^{*}$ comparison of the mean warfarin dose per age group with $\mathrm{n} \geq 3$

The difference in the findings of this study is strongly associated with the limitations of the inclusion criteria, which is cardiovascular disease treated with warfarin. The same findings were shown in a pharmacogenomic study at one of the national referral hospitals for cardiovascular disease management, in which warfarin was mostly used for male patients (55.3\%) (Suriapranata et al., 2011).

Meanwhile, the top three diseases for which warfarin was prescribed included CHF, CHF-AF, and AF. Warfarin administration to patients with CHF has proved to be able to reduce the risk of both systemic complications and venous thromboembolism (Siliste et al., 2018). The use of warfarin has also proved to be effective in preventing thromboembolism among patients with atrial fibrillation at I-A level of evidence (Katritsis et al., 2015). It has been acknowledged that warfarin use for the top three indications in this study was intended to achieve the INR therapeutic target of 2.0-3.0. The principle of warfarin administration refers to the effective lowest dose to achieve and maintain the target of international normalized ratio (INR), which varies depending on the disease indications (Kuruvilla \& GurkTurner, 2001). The recommended range of warfarin dose is $2-5 \mathrm{mg} /$ day as initial therapy and $2-10 \mathrm{mg}$ /day for maintenance by referring to INR or prothrombin time (PT) ratio as the underlying consideration for dose adjustment. The average dose of warfarin for each indication based on the age group of the patients involved in this study is described (Table II). The daily dose of warfarin per patient ranging from 0.20 to $4.50 \mathrm{mg}$ per day $(1.83 \pm 0.54 \mathrm{mg} /$ day on average $)$ with the highest dose (4 mg/day) for Mitral Valve Replacement (MVR) in elderly patients (Table II). Meanwhile, antiphospholipid antibody syndrome (APS) cases after cesarean section in adult patients are treated with the lowest dose of warfarin $(0.36 \mathrm{mg} /$ day $)$. Both of such indications were found in only 1 case during the 2 -years of the research. 
Vitarani D.A Ningrum

Table III. Incidence of bleeding associated with warfarin use

\begin{tabular}{|c|c|c|c|c|c|c|c|c|}
\hline \multirow[b]{2}{*}{ Sex/Age } & \multirow{2}{*}{$\begin{array}{l}\text { Medical } \\
\text { History }\end{array}$} & \multirow{2}{*}{$\begin{array}{l}\text { Days of } \\
\text { Treatment }\end{array}$} & \multirow{2}{*}{$\begin{array}{c}\text { Dose } \\
\text { (mg/day) }\end{array}$} & \multicolumn{3}{|c|}{ Laboratory Test Results } & \multirow{2}{*}{$\begin{array}{c}\text { Interaction } \\
\text { with other } \\
\text { Drugs }\end{array}$} & \multirow{2}{*}{$\begin{array}{c}\text { Level of } \\
\text { Interaction }\end{array}$} \\
\hline & & & & $\begin{array}{c}\text { INR } \\
(0.8-1.2)\end{array}$ & $\begin{array}{l}\text { Hemoglobin } \\
(14-18 \mathrm{~g} / \mathrm{dL})\end{array}$ & $\begin{array}{c}\text { Thrombocyte } \\
(150-440 \mathrm{k} / \mu \mathrm{L})\end{array}$ & & \\
\hline \multirow{8}{*}{$\begin{array}{l}\text { Male/70 } \\
\text { years }\end{array}$} & \multirow{8}{*}{ 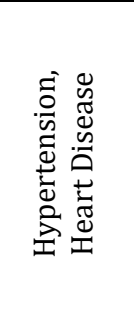 } & $1^{*}$ & & - & $4.5 \mathrm{~g} / \mathrm{dL}$ & $357 \mathrm{k} / \mu \mathrm{L}$ & & \\
\hline & & 2 & & - & - & - & & \\
\hline & & $3^{*}$ & & 6.77 & - & - & & \\
\hline & & 4 & $\begin{array}{c}\text { Not } \\
\text { dministered }\end{array}$ & - & - & - & Allopurinol & Moderate \\
\hline & & 5 & administered & - & $13.9 \mathrm{~g} / \mathrm{dL}$ & - & & \\
\hline & & 6 & & 5.95 & - & - & & \\
\hline & & 7 & & 3.37 & - & - & & \\
\hline & & 8 & 2 & - & - & - & $\begin{array}{l}\text { Allopurinol, } \\
\text { Lansoprazole }\end{array}$ & Moderate \\
\hline \multirow[t]{10}{*}{$\begin{array}{l}\text { Male/77 } \\
\text { years }\end{array}$} & & 1 & $\begin{array}{c}\text { Not } \\
\text { administered }\end{array}$ & 1.11 & $10.7 \mathrm{~g} / \mathrm{dL}$ & $240 \mathrm{k} / \mu \mathrm{L}$ & - & - \\
\hline & & 2 & & - & - & - & & \\
\hline & & 3 & 2 & - & - & - & & \\
\hline & $\frac{0}{y}$ & 4 & & 1.37 & - & - & Asnirin & \\
\hline & $\stackrel{\Xi}{ \pm}$ & 5 & 3 & - & $11.7 \mathrm{~g} / \mathrm{dL}$ & $200 \mathrm{k} / \mu \mathrm{L}$ & $\begin{array}{c}\text { Aspırın } \\
\text { Ranitidine }\end{array}$ & $\begin{array}{l}\text { Major } \\
\text { Moderate }\end{array}$ \\
\hline & $\stackrel{\bar{\Xi}}{\grave{\lambda}}$ & $\begin{array}{l}6 \\
7\end{array}$ & & - & - & - & & \\
\hline & 工 & $\begin{array}{l}7 \\
8\end{array}$ & 3 & $\begin{array}{l}- \\
-\end{array}$ & $\begin{array}{l}- \\
-\end{array}$ & $\begin{array}{l}- \\
-\end{array}$ & & \\
\hline & & $9 *$ & & - & - & - & & \\
\hline & & 10 & Halted & 6.29 & $10.7 \mathrm{~g} / \mathrm{dL}$ & $306 \mathrm{k} / \mu \mathrm{L}$ & Ranitidine & Moderate \\
\hline & & 11 & - & 5.72 & - & - & - & - \\
\hline \multirow{11}{*}{$\begin{array}{l}\text { Male/70 } \\
\text { years }\end{array}$} & & 1 & & - & $14.2 \mathrm{~g} / \mathrm{dL}$ & $289 \mathrm{k} / \mu \mathrm{L}$ & Ranitidine & Moderate \\
\hline & $\stackrel{\infty}{n}$ & 2 & & 0.91 & - & - & Aspirin & Maior \\
\hline & $g$ & 3 & & 1.02 & - & - & $\begin{array}{c}\text { Aspirın } \\
\text { Ranitidine }\end{array}$ & $\begin{array}{l}\text { Major } \\
\text { Moderate }\end{array}$ \\
\hline & 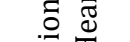 & 4 & & - & - & - & & \\
\hline & $\overline{\tilde{n}} I$ & $5^{*}$ & & - & - & - & & \\
\hline & 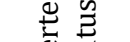 & 6 & 2 & - & - & - & & \\
\hline & 气 & 7 & & - & - & - & Aspirin & Major \\
\hline & $\gtrsim \sum$ & 8 & & - & - & - & Ranitidine & Moderate \\
\hline & 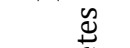 & $9^{*}$ & & - & - & - & Ceftriaxone & Moderate \\
\hline & 0 & 10 & & - & - & - & & \\
\hline & $\stackrel{\pi}{\pi}$ & 11 & & - & - & - & & \\
\hline Male/64 & & 1 & 2 & - & - & - & & \\
\hline \multirow{12}{*}{ years } & $\pi$ & 2 & 2 & - & - & - & & \\
\hline & 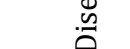 & 3 & 2 & 0.96 & - & - & & \\
\hline & & 4 & 2 & - & 11.6 & $165 \mathrm{k} / \mu \mathrm{L}$ & & \\
\hline & ఏే ప & 5 & 1 & - & - & - & & \\
\hline & 至 & 6 & 1 & - & - & - & & \\
\hline & 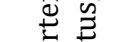 & 7 & 1 & - & - & - & Aspirin & Major \\
\hline & $\overline{\mathrm{\Xi}}$ & 8 & 1 & - & - & - & & \\
\hline & 초 & 9 & 1 & - & - & - & & \\
\hline & $£$ & 10 & 1 & - & - & - & & \\
\hline & $\stackrel{\square}{0}$ & 11 & 1 & - & - & - & & \\
\hline &.$\pi$ & 12 & 1 & - & - & - & & \\
\hline & & 13 & $1 *$ & Halted & - & - & & \\
\hline
\end{tabular}

*Bleeding 
The warfarin dose for patients with MVR in this study (28 mg/week) is comparable to the results of a retrospective cohort study involving 200 MVR patients with an average warfarin dose of $25.6 \pm 9.5 \mathrm{mg} /$ week. The study found the incidence of thromboembolism in 11 patients, and 12 patients experienced bleeding (Kamthornthanakarn \& Krittayaphong, 2019). A study however, has limitations in that the retrospective cross-sectional design it used makes it unable to reveal the clinical outcomes of warfarin use in such cases. In principle, the use of anticoagulants, including warfarin, in MVR cases is aimed to minimize postoperative thromboembolic complications while maintaining the therapeutic level with a minimum risk of bleeding (Erwin \& Iung, 2018). Meanwhile, warfarin with the lowest dose in postpartum APS cases, but not during pregnancy as it can carry the risk of embryopathy, can be administered for 4-6 weeks (Ernest et al., 2011; Myers \& Pavord, 2011) with a target INR of 2.0 - 3.0 or INR target $>3.0$ for patients with a high risk of recurrence and/or arterial thrombosis (Del Papa \& Vaso, 2010).

In addition, this present study identified the average doses of warfarin for all indications in the elderly and adult groups that reached $1.87 \pm 0.50$ $\mathrm{mg} /$ day and $1.77 \pm 0.59 \mathrm{mg} /$ day, respectively $(\mathrm{p}$ : $0.175)$. It is well established that age is not associated with warfarin dose because there is no significant difference in the pharmacokinetic profiles between elderly and adult patients. However, there is stronger evidence of warfarin inhibiting the synthesis of vitamin K-dependent clotting factors II, VII, IX, and X in the elderly group despite comparable warfarin concentrations in plasma. Therefore, to achieve the clinical response target, a lower dose is required for elderly patients (Mangoni \& Jackson, 2004). However, the exact mechanism responsible for improving the sensitivity of warfarin remains unknown (Shepherd et al., 1977). This study found a significant difference in the mean warfarin dose between the adult and elderly groups having $\mathrm{CHF}$ and AF $(\mathrm{p}<0.05)$ with the highest mean dose unexpectedly discovered in the majority of the elderly patients.

Contrary to this research, two studies of warfarin use revealed that the elderly received a lower warfarin dose as opposed to the adult group with $4.6 \pm 2.0 \mathrm{mg} /$ day vs $6.8 \pm 2.8 \mathrm{mg} /$ day and $3.34 \pm 1.71 \mathrm{mg} /$ day vs $3.26 \pm 1.27 \mathrm{mg} /$ day (de Padua Mansur et al., 2012; Shendre et al., 2018). Another study involving 102 Japanese patients also found similar results although with an insignificant difference, in which the average dose of warfarin for adult patients was higher $(2.86 \pm 1.2 \mathrm{mg} /$ day $)$ compared to that for patients aged $\geq 65$ years $(2.76 \pm 0.98 \mathrm{mg} /$ day) (Miura et al., 2009). In the meantime, 11,835 Korean patients also received warfarin at a lower average dose than Caucasian patients, at 3.38+-1.06 mg/day, but still higher than those in the studies of Japanese and Indonesian patients. This finding is likely associated with the higher vitamin $\mathrm{K}$ intake that Koreans consume daily (Kim et al., 2019). Through the administration of a higher dose, this study has yet to be able to comprehensively show the level of effectiveness and safety of warfarin in elderly patients.

In addition, along with the study that involved Japanese patients, this present study also confirms the higher sensitivity of warfarin among Asian patients compared to Caucasians, thereby making them receive a lower average dose than that for Caucasians (Dang et al., 2005). Such fact is associated with the evidence that, at the same PTINR values, the incidence of bleeding is more frequent among Asians compared to Caucasian patients. Therefore, various predictive models are involved in estimating safe and effective individual maintenance dose of warfarin through such variables as genetic variation of CYP2C9 and VKORC1 coding genes as well as patient characteristics (age, ethnicity, diet, and body mass index). These variables, including warfarin drug interactions, should be considered in the estimation of initial dose, maintenance dose, or dose adjustment on the fourth or fifth day of warfarin use (Eriksson \& Wadelius, 2012). Nonetheless, a prospective cohort study involving 1015 patients indicated that the use of various algorithms for optimum warfarin dose requirements cannot be fully implemented yet as there are exceptions, particularly for patients with $\mathrm{CHF}$, mainly during the first four weeks of therapy (Kasner et al., 2016).

Meanwhile, research on the approach of warfarin dose involving Indonesian patients was conducted in two studies with a total of 186 participants. Both showed mutually reinforcing findings and proved that other than age, genetic variation of VKORC1 and CYP2C9 correlates significantly with the pharmacokinetics and pharmacodynamics of warfarin based on PT-INR parameters (Rusdiana et al., 2013; Suriapranata et al., 2011). Although PT-INR is known to be the parameters of therapeutic target and risk of bleeding, their testing has yet to be scheduled 
periodically in any hospitals in Indonesia. There were only 39 INR tests conducted at the study site, with $64.1 \%$ performed on patients receiving warfarin dose of 1-2 mg/day. The limitations of the study design have restricted a further analysis of the obtained INR data. Regarding the frequency of INR testing, the American Heart Association recommends that INR monitoring should be conducted periodically soon after beginning the warfarin therapy until the correlation of dose and response becomes stable; after that, the frequency of INR tests can be reduced (Hirsh Jack et al., 2003). To date, INR testing service in Indonesia has not been able to implement such recommendation, including the health facilities at peripheral level that do not even have adequate facilities (Perhimpunan Dokter Spesialis Kardiovaskular Indonesia, 2014). As previously mentioned, the average dose of warfarin in this study was relatively lower than that for Caucasian patients. However, the incidence of bleeding was also found during the study (Table III).

Four patients receiving warfarin experienced bleeding clinically manifested as hematuria $(100 \%)$, and one patient experienced both hematuria and melena (25\%). The first patient had bleeding when admitted to hospital with melena and hematuria on the third day of treatment. The INR test was performed on the third day, resulting in 6.77 , which continued to decline until the seventh day of treatment. As predicted, the incidence of bleeding occurs in patients with relatively high INR. Similarly, a study of 133 patients found that INR $\geq 5$ becomes one of the significant variables of bleeding incidence (Teklay et al., 2014), which is the same with research on 472 patients with INR $\geq 4$ (Hylek et al., 2007). It was found that the cause of bleeding in these patients was the routine use of drugs from the hospital consisting of candesartan, bisoprolol, and warfarin without routine INR monitoring, making it difficult to determine when the drug administration should be halted. Routine INR monitoring can reduce the frequency of adverse events due to warfarin use with an odds ratio of 1.48 - 1.73 (Krumholz et al., 2016).

In addition, monitoring the use of warfarin, particularly in outpatients for whom direct and routine monitoring from medical staff is unavailable, has proved to increase the clinical outcomes (Sudas et al., 2018). After reaching 3.37 INR, patients can resume using warfarin at a dose of $2 \mathrm{mg} /$ day. With regard to drug interactions, the two drugs routinely administered to the patients have an insignificant influence on the pharmacokinetics and pharmacodynamics of warfarin (Holbrook et al., 2005). Other factors possibly contributing to the incidence of bleeding, such as interaction with foods or the use of herbal medicine (Ge et al., 2014), cannot be well identified due to the limitations of this retrospective study. The first patient had not only hematuria but also melena. This finding is consistent with a retrospective cohort study involving 401 patients who used warfarin with melena as a bleeding risk factor and aged more than 65 years (RR 2.5). This first patient resumed receiving warfarin after bleeding. Further intensive monitoring should be conducted since the possibility of bleeding (27.3\%) is higher compared to that of thromboembolism (16.7\%) following post-bleeding warfarin readministration (Chen et al., 2014).

Meanwhile, the second patient experienced hematuria on the ninth day after receiving warfarin on the second day at a dose of $2 \mathrm{mg} /$ day, which was then increased to $3 \mathrm{mg} /$ day on the fourth day of treatment when the INR increased by 0.26 . Warfarin was not administered on the first day possibly because the patient's INR remained in therapeutic target range. In addition to the risk factor for hypertension, the patient was aged $\geq 75$ years and received a combination with aspirin (Turan et al., 2016) as well as experienced anemia (Ali et al., 2016). The interaction of warfarin and aspirin has a major interaction level which indicates that the effect can potentially be lifethreatening or cause permanent damage. This interaction can increase INR, thereby leading to the risk of bleeding because aspirin affects platelet function. Incidence of bleeding in patients using warfarin combined with aspirin increases 9-fold when compared to warfarin monotherapy (Bungard et al., 2011; Teklay et al., 2014; Uygungül et al., 2014). Setting a lower INR target can be considered when patients receive a combination with aspirin (Kim et al., 2019).

The third patient who also experienced hematuria had an INR value below the therapeutic target on the second and third day with 0.91 and 1.02 INR, respectively. Data limitations of patient characteristics in this study, including BMI which is known to have a higher requirement of warfarin weekly dose to reach the therapeutic target of INR (Tellor et al., 2018), remain unknown. Even though the patient has not reached INR therapeutic target with a likely risk of thromboembolism, the patient experienced bleeding on the fifth and ninth day. The patient still received $2 \mathrm{mg}$ warfarin per day 
until the last day of treatment. It was not well identified whether the hematuria in this patient was caused by warfarin or his urinary tract infection or even a combination of both (Bolenz et al., 2018) since no INR testing was performed when the patient was bleeding. Similar to the previous elderly patient, a combination with aspirin appears to be requiring INR target adjustment.

In addition, the last patient who also experienced hematuria had anemia as a risk factor $(11.6 \mathrm{~g} / \mathrm{dL})$ and received combination therapy with aspirin. Relating to the patient's age of $<65$ years, a study of 2046 patients who received warfarin proved a lower risk of bleeding compared to other groups (Yokoyama et al., 2018). Nonetheless, the patient had anemia and still received warfarin at a lower dose of $1 \mathrm{mg} /$ day since his INR (0.95) still carried the risk of developing thromboembolism. On the thirteenth day of treatment, however, the patient developed hematuria without further INR testing.

The study found the incidence of bleeding in four patients with an average age of $70.25 \pm 5.32$ years. Hematuria becomes a clinical manifestation of major bleeding in warfarin users, which is also found in a retrospective cross-sectional study involving 96 patients (58.82\%) (Ozturk et al., 2019). In addition to the elderly age, heart disease and hypertension are associated with an increased risk of bleeding in treatment with warfarin which is also found in these four patients (Shoeb \& Fang, 2013).

Compared to warfarin users at a younger age, the relative risk of bleeding increases by $31 \%$ in elderly patients, thereby requiring some strategies to reduce the incidence of bleeding (Shendre et al., 2018). This incidence is mainly related to the dose, including when a combination with aspirin is required to achieve the lower therapeutic target of INR for Indonesians. A lower INR target based on the incidence of bleeding and thromboembolism is found in a retrospective cohort study involving Chinese patients using warfarin, reaching 1.8 - 2.4 INR (You et al., 2005). Although the genetic profile of VKORC1 and CYP2C9 has been recommended as a dose predictor, pharmacoeconomic studies should be conducted by comparing the use of warfarin with genetic testing and the use of DOACs (direct oral anticoagulants) (Bounameaux \& Reber, 2010) although a study of 3731 patients found no significant differences in major bleeding incidence between DOAC and warfarin (Bialkowski et al., 2020).
This study has a number of limitations, including the non-randomized selection of the study site and the INR test that was not done to all of the patients, thereby resulting in nonrepresentative incidence of warfarin ADR among the patient populations in all secondary hospitals. Another limitation is that, despite the efforts to involve all of the patients who met the inclusion criteria, this retrospective cross-sectional study was unable to identify the correlation between INR values as the target of warfarin therapy and patient demographics. Therefore, a longitudinal study with routine INR tests that involves patients in a moreextensive area is recommended to provide a safe and effective approach to a disease management using warfarin. The resulted means of warfarin dose, which are relatively lower than those found in the studies of Caucasians require a further study of the appropriate therapeutic dose range for Indonesian patients. In addition, the incidence of bleeding among patients given aspirin combination indicates the need to target lower INR values, particularly for elderly patients.

\section{CONCLUSION}

The top three indications of warfarin use include $\mathrm{CHF}, \mathrm{CHF}-\mathrm{AF}$, and AF with an average dose of $1.83 \pm 0.54 \mathrm{mg} /$ day. Warfarin-associated bleeding was experienced by the elderly patients, and only less than $5 \%$ patients experienced hematuria as the main clinical manifestation. However, periodic INR monitoring is required as a strategy to prevent bleeding incidence and an approach to adjust warfarin doses, particularly for patients with risk factors, such as elderly patients and patients receiving combination therapy with aspirin.

\section{ACKNOWLEDGEMENT}

This research was funded by the Pharmacist Professional Study Program of Universitas Islam Indonesia through the 2019 Collaborative Research Grant No. 465/Ka.Prog.Apt./20/Prog.Apt./XI/2019.

\section{REFERENCES}

Agustini, T. T., Arifin, H., \& Hanif, A. M. (2016). Comparison between Warfarin Dose and Duration of Achieving Target INR in CHF Patients with Atrial Fibrillation. Jurnal Sains Farmasi \& Klinis, 2(2), 162-170. https://doi.org/10.29208/jsfk.2016.2.2.67

Ali, A. N., Athavale, N. V., \& Abdelhafiz, A. H. (2016). Anemia: An Independent Predictor of 
Adverse Outcomes In Older Patients With Atrial Fibrillation. Journal of Atrial Fibrillation, https://doi.org/10.4022/jafib.1366

Bialkowski, W., Tan, S., Mast, A. E., Kiss, J. E., Kor, D., Gottschall, J., Wu, Y., Roubinian, N., Triulzi, D., Kleinman, S., Choi, Y., Brambilla, D., Zimrin, A., \& NHLBI Recipient Epidemiology and Donor Evaluation (REDS)-III Study. (2020). Equivalent inpatient mortality among direct-acting oral anticoagulant and warfarin users presenting with major hemorrhage. Thrombosis Research, 185, 109-118.

https://doi.org/10.1016/j.thromres.2019.1 1.024

Bolenz, C., Schröppel, B., Eisenhardt, A., J. SchmitzDräger, B., \& Grimm, M.-0. (2018). The Investigation of Hematuria. Deutsches Ärzteblatt International, 115(48), 801-807. https://doi.org/10.3238/arztebl.2018.0801

Bounameaux, H., \& Reber, G. (2010). New oral antithrombotics: A need for laboratory monitoring. Against. Journal of Thrombosis and Haemostasis, 8(4), 627-630. https://doi.org/10.1111/j.15387836.2010.03759.x

Bungard, T. J., Yakiwchuk, E., Foisy, M., \& Brocklebank, C. (2011). Drug Interactions Involving Warfarin: Practice Tool and Practical Management Tips. Canadian Pharmacists Journal / Revue Des Pharmaciens Du Canada, 144(1), 21-25.e9. https://doi.org/10.3821/1913-701X144.1.21

Canestaro, W.J., Patrick, A.R., Avorn, J., Ito, K., Matlin, O.S., Brennan, T.A., Shrank, W.H., \& Choudhry, N.K. (2013). Cost-Effectiveness of Oral Anticoagulants for Treatment of Atrial Fibrillation. Circulation: Cardiovascular Quality and Outcomes, 6(6), 724-731. https://doi.org/10.1161/CIRCOUTCOMES.1 13.000661

Chen, W.-C., Chen, Y.-H., Hsu, P.-I., Tsay, F.-W., Chan, H.-H., Cheng, J.-S., \& Lai, K.-H. (2014). Gastrointestinal Hemorrhage in Warfarin Anticoagulated Patients: Incidence, Risk Factor, Management, and Outcome. BioMed Research International, 2014. https://doi.org/10.1155/2014/463767

Dang, M.-T. N., Hambleton, J., \& Kayser, S. R. (2005). The influence of ethnicity on warfarin dosage requirement. The Annals of
Pharmacotherapy, 39(6), 1008-1012. https://doi.org/10.1345/aph.1E566

de Padua Mansur, A., Takada, J. Y., Avakian, S. D., \& Strunz, C. M. C. (2012). Warfarin doses for anticoagulation therapy in elderly patients with chronic atrial fibrillation. Clinics, 67(6), 543-546. https://doi.org/10.6061/clinics/2012(06)0 1

Del Papa, N., \& Vaso, N. (2010). Management of Antiphospholipid Syndrome. Therapeutic Advances in Musculoskeletal Disease, 2(4), 221-227.

https://doi.org/10.1177/1759720X103659 69

Eriksson, N., \& Wadelius, M. (2012). Prediction of warfarin dose: Why, when and how? Pharmacogenomics, 13(4), 429-440. https://doi.org/10.2217/pgs.11.184

Ernest, J. M., Marshburn, P. B., \& Kutteh, W. H. (2011). Obstetric antiphospholipid syndrome: An update on pathophysiology and management. Seminars in Reproductive Medicine, 29(6), 522-539. https://doi.org/10.1055/s-0031-1293206

Erwin, J. P., \& Iung, B. (2018). Current recommendations for anticoagulant therapy in patients with valvular heart disease and atrial fibrillation: The ACC/AHA and ESC/EACTS Guidelines in Harmony...but not Lockstep! Heart, 104(12), 968-970. https://doi.org/10.1136/heartjnl-2017312758

Furdiyanti, N. H., Pramantara, I. D. P., \& Wahyono, D. (2014). Evaluation of Warfarin Dosing and Its Clinical Outcome in Outpatients (Journal of Management and Pharmacy Practice), 4(3), 175-179. https://doi.org/10.22146/jmpf.284

Ge, B., Zhang, Z., \& Zuo, Z. (2014). Updates on the Clinical Evidenced Herb-Warfarin Interactions. Evidence-Based Complementary and Alternative Medicine: ECAM, 2014. https://doi.org/10.1155/2014/957362

Hirsh Jack, Fuster Valentin, Ansell Jack, \& Halperin Jonathan L. (2003). American Heart Association/American College of Cardiology Foundation Guide to Warfarin Therapy. Circulation, 107(12), 1692-1711. https://doi.org/10.1161/01.CIR.00000635 75.17904.4E

Holbrook, A. M., Pereira, J. A., Labiris, R., McDonald, H., Douketis, J. D., Crowther, M., \& Wells, P. S. 
(2005). Systematic Overview of Warfarin and Its Drug and Food Interactions. Archives of Internal Medicine, 165(10), 1095-1106. https://doi.org/10.1001/archinte.165.10.1 095

Hylek, E. M., Evans-Molina, C., Shea, C., Henault L. E., \& Regan S. (2007). Major Hemorrhage and Tolerability of Warfarin in the First Year of Therapy Among Elderly Patients With Atrial Fibrillation. Circulation, 115(21), 26892696.

https://doi.org/10.1161/CIRCULATIONAH A.106.653048

Kamthornthanakarn, I., \& Krittayaphong, R. (2019). Optimal INR level for warfarin therapy after mechanical mitral valve replacement. $B M C$ Cardiovascular Disorders, 19. https://doi.org/10.1186/s12872-0191078-3

Kasner, S. E., Wang, L., French, B., Messé, S. R., Ellenberg, J., \& Kimmel, S. E. (2016). Warfarin Dosing Algorithms and the Need for Human Intervention. The American Journal of Medicine, 129(4), 431-437. https://doi.org/10.1016/j.amjmed.2015.11. 012

Katritsis, D. G., Gersh, B. J., \& Camm, A. J. (2015). Anticoagulation in Atrial Fibrillation Current Concepts. Arrhythmia \& Electrophysiology Review, 4(2), 100-107. https://doi.org/10.15420/aer.2015.04.02.1 00

Kemenkes RI. (2019a). Petunjuk Teknis Standar Pelayanan Kefarmasian di Rumah Sakit. http://farmalkes.kemkes.go.id/2020/01/p etunjuk-teknis-standar-pelayanankefarmasian-di-rumah-sakit/

Kemenkes RI, B. P. dan P. K. (2019b). Hasil Utama Riskesdas 2018.

Khalili, H., Dashti-Khavidaki, S., Talasaz, A. H.-H., Najmedin, F., \& Hosseinpoor, R. (2010). Anticoagulant utilization evaluation in a teaching hospital: A prospective study. Journal of Pharmacy Practice, 23(6), 579584.

https://doi.org/10.1177/08971900103728 08

Kim, Y., Park, E. S., Kang, D.-W., Kim, T. J., \& Lee, S.H. (2019). Maintenance dose of warfarin beyond time in therapeutic range for preventing vascular events. Journal of the Neurological Sciences, 398, 69-74. https://doi.org/10.1016/j.jns.2019.01.031
Krumholz, H. M., Bona, R., Jaser, L., Classen, D., Wang, Y., Eldridge, N., Metersky, M. L., Metersky, M. L., Eckenrode, S., Bakullari, A., \& Andrawis, M. (2016). Predictors of warfarin-associated adverse events in hospitalized patients: Opportunities to prevent patient harm. Journal of Hospital Medicine, 11(4). https://doi.org/10.1002/jhm.2528

Kuruvilla, M., \& Gurk-Turner, C. (2001). A review of warfarin dosing and monitoring. Proceedings (Baylor University. Medical Center), 14(3), 305-306. https://www.ncbi.nlm.nih.gov/pmc/article s/PMC1305837/

Laäs, D. J., \& Naidoo, M. (2018). An evaluation of warfarin use at an urban district-level hospital in KwaZulu-Natal Province, South Africa. South African Medical Journal, 108(12), 1046-1050-1050. https://doi.org/10.7196/SAMJ.2018.v108i1 2.13256

Mak, M., Lam, C., Pineda, S. J., Lou, M., Xu, L. Y., Meeks, C., Lin, C., Stone, R., Rodgers, K., \& Mitani, G. (2019). Pharmacogenetics of Warfarin in a Diverse Patient Population. Journal of Cardiovascular Pharmacology and Therapeutics, 24(6), 521-533. https://doi.org/10.1177/10742484198435 30

Mangoni, A. A., \& Jackson, S. H. D. (2004). Agerelated changes in pharmacokinetics and pharmacodynamics: Basic principles and practical applications. British Journal of Clinical Pharmacology, 57(1), 6-14. https://doi.org/10.1046/j.13652125.2003.02007.x

Miura, T., Nishinaka, T., Terada, T., \& Yonezawa, K. (2009). Relationship between aging and dosage of warfarin: The current status of warfarin anticoagulant therapy for Japanese outpatients in a department of cardiovascular medicine. Journal of Cardiology, 53(3), 355-360. https://doi.org/10.1016/j.jjcc.2008.12.003

Mosca, L., Barrett-Connor, E., \& Kass Wenger, N. (2011). Sex/Gender Differences in Cardiovascular Disease Prevention: What a Difference a Decade Makes. Circulation, 124(19), 2145-2154. https://doi.org/10.1161/CIRCULATIONAH A.110.968792

Myers, B., \& Pavord, S. (2011). Diagnosis and management of antiphospholipid syndrome 
in pregnancy. The Obstetrician \& Gynaecologist, 13(1), 15-21. https://doi.org/10.1576/toag.13.1.15.2763 6

Ozturk, M., Ipekci, A., Kiyak, S. K., Akdeniz, Y. S., Aydin, Y., Ikizceli, I., \& Sogut, O. (2019). Bleeding Complications in Warfarin-Treated Patients Admitted to the Emergency Department. Journal of Clinical Medicine Research, 11(2), 106-113. https://doi.org/10.14740/jocmr3669

Perhimpunan Dokter Spesialis Kardiovaskular Indonesia. (2014). Pedoman Tata Laksana Fibrilasi Atrium. 99.

Putri, N. A., Lestari, K., Diantini, A., \& Rusdiana, T. (2012). Warfarin Therapy Monitoring of Cardiac Care Patients in Hospital in Bandung. Indonesian Journal of Clinical Pharmacy, 1(3), 110-116. http://jurnal.unpad.ac.id/ijcp/article/view $/ 12675$

Ritschel, W., \& Kearns, G. (2004). Handbook of Basic Pharmacokinetics Including Clinical Applications (sixth). American Pharmacist Association.

Ruff, C. T., Giugliano, R. P., Braunwald, E., Hoffman, E. B., Deenadayalu, N., Ezekowitz, M. D., Camm, A. J., Weitz, J. I., Lewis, B. S., Parkhomenko, A., Yamashita, T., \& Antman, E. M. (2014). Comparison of the efficacy and safety of new oral anticoagulants with warfarin in patients with atrial fibrillation: A meta-analysis of randomised trials. Lancet (London, England), 383(9921), 955-962. https://doi.org/10.1016/S01406736(13)62343-0

Rusdiana, T., Araki, T., Nakamura, T., Subarnas, A., \& Yamamoto, K. (2013). Responsiveness to low-dose warfarin associated with genetic variants of VKORC1, CYP2C9, CYP2C19, and CYP4F2 in an Indonesian population. European Journal of Clinical Pharmacology, 69(3), 395-405. https://doi.org/10.1007/s00228-0121356-9

Semakula, J. R., Mouton, J. P., Jorgensen, A., Hutchinson, C., Allie, S., Semakula, L., French, N., Lamorde, M., Toh, C.-H., Blockman, M., Sekaggya-Wiltshire, C., Waitt, C., Pirmohamed, M., \& Cohen, K. (2020). A cross-sectional evaluation of five warfarin anticoagulation services in Uganda and South Africa. PLOS ONE, 15(1), e0227458. https://doi.org/10.1371/journal.pone.0227 458

Shendre, A., Parmar, G. M., Dillon, C., Beasley, T. M., \& Limdi, N. A. (2018). Influence of age on warfarin dose, anticoagulation control, and risk of hemorrhage. Pharmacotherapy, 38(6), 588-596. https://doi.org/10.1002/phar.2089

Shepherd, A. M., Hewick, D. S., Moreland, T. A., \& Stevenson, I. H. (1977). Age as a determinant of sensitivity to warfarin. British Journal of Clinical Pharmacology, 4(3), 315-320. https://www.ncbi.nlm.nih.gov/pmc/article s/PMC1429084/

Shoeb, M., \& Fang, M. C. (2013). Assessing Bleeding Risk in Patients Taking Anticoagulants. Journal of Thrombosis and Thrombolysis, 35(3), 312-319.

Siliste, R.-N., Antohi, E.-L., Pepoyan, S., Nakou, E., \& Vardas, P. (2018). Anticoagulation in heart failure without atrial fibrillation: Gaps and dilemmas in current clinical practice. European Journal of Heart Failure, 20(6), 978-988. https://doi.org/10.1002/ejhf.1153

Sudas N. A, N., Sakunrak, I., \& Dhippayom, T. (2018). Clinical Outcomes of Telemonitoring for Patients on Warfarin after Discharge from Hospital [Clinical Study]. International Journal of Telemedicine and Applications; Hindawi. https://doi.org/10.1155/2018/7503421

Suriapranata, I. M., Tjong, W. Y., Wang, T., Utama, A., Raharjo, S. B., Yuniadi, Y., \& Tai, S. S. (2011). Genetic factors associated with patientspecific warfarin dose in ethnic Indonesians. BMC Medical Genetics, 12(1), 80. https://doi.org/10.1186/1471-2350-12-80

Ta Michael Lee, M., \& Klein, T. E. (2013). Pharmacogenetics of warfarin: Challenges and opportunities. Journal of Human Genetics, 58(6), 334-338. https://doi.org/10.1038/jhg.2013.40

Teklay, G., Shiferaw, N., Legesse, B., \& Bekele, M. L. (2014). Drug-drug interactions and risk of bleeding among inpatients on warfarin therapy: A prospective observational study. Thrombosis Journal, 12(1), 20. https://doi.org/10.1186/1477-9560-12-20

Tellor, K. B., Nguyen, S. N., Bultas, A. C., Armbruster, A. L., Greenwald, N. A., \& Yancey, A. M. (2018). Evaluation of the impact of body mass index on warfarin requirements in hospitalized patients. Therapeutic Advances 
in Cardiovascular Disease, 12(8), 207-216. https://doi.org/10.1177/17539447187812 95

Turan, B., Demir, H., Mutlu, A., Daşlı, T., Erkol, A., \& Erden, İ. (2016). Inappropriate combination of warfarin and aspirin. Anatolian Journal of Cardiology, 16(3), 189-196. https://doi.org/10.5152/akd.2015.6050

Uygungül, E., Ayrik, C., Narci, H., Erdoğan, S., Toker, İ., Demir, F., \& Karaaslan, U. (2014). Determining Risk Factors of Bleeding in Patients on Warfarin Treatment. Advances in Hematology,

2014. https://doi.org/10.1155/2014/369084

World Health Organization, W. H. (2003). Drug and therapeutics committees: A practical guide. (WHO/EDM/PAR/2004.1). Article WHO/EDM/PAR/2004.1.

https://apps.who.int/iris/handle/10665/6 8553
Wysowski, D. K., Nourjah, P., \& Swartz, L. (2007). Bleeding complications with warfarin use: A prevalent adverse effect resulting in regulatory action. Archives of Internal Medicine, 167(13), 1414-1419.

Yokoyama, S., Tanaka, Y., Nakagita, K., Hosomi, K., \& Takada, M. (2018). Bleeding Risk of Warfarin and Direct Oral Anticoagulants in Younger Population: A Historical Cohort Study Using a Japanese Claims Database. International Journal of Medical Sciences, 15(14), 16861693. https://doi.org/10.7150/ijms.28877

You, J. H. S., Chan, F. W. H., Wong, R. S. M., \& Cheng, G. (2005). Is INR between 2.0 and 3.0 the optimal level for Chinese patients on warfarin therapy for moderate-intensity anticoagulation? British Journal of Clinical Pharmacology, 59(5), 582-587. https://doi.org/10.1111/j.1365-

2125.2005.02361.x 